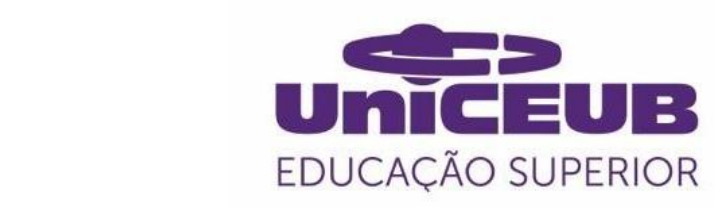

CENTRO UNIVERSITÁRIO DE BRASÍLIA- UnICEUB

PROGRAMA DE INICIAÇÃO CIENTÍFICA

MATHIAS DE SOUSA LUZ

HANNA KAMAL HUSNI

O IMPACTO DA NEUROARQUITETURA EM ESTABELECIMENTOS ASSISTENCIAIS DE SAÚDE (EAS)

BRASÍLIA

2020 


\section{บกाट $=\mathbf{B}$ \\ EDUCAÇÃO SUPERIOR}

\section{MATHIAS DE SOUSA LUZ}

HANNA KAMAL HUSNI

\section{O IMPACTO DA NEUROARQUITETURA EM ESTABELECIMENTOS ASSISTENCIAIS DE SAÚDE (EAS)}

Relatório final de pesquisa de Iniciação Científica apresentado à Assessoria de PósGraduação e Pesquisa.

Orientação: Eliete de Pinho Araujo

BRASÍLIA 


\section{DEDICATÓRIA}

Dedicamos a todos os professores do UniCEUB que nos influenciaram em nossa trajetória. Em especial à professora Eliete, com quem compartilhamos nossas dúvidas e angústias, que nos manteve focados na trilha certa para a conclusão deste projeto. Aos palestrantes das oficinas feitas pela Assessoria de Pós-graduação e Pesquisas. Fazemos também essa dedicatória para aqueles que perderam algum ente querido no ano de 2020 em função da Covid-19. 


\section{AGRADECIMENTOS}

Primeiramente gostaríamos de agradecer a Deus, sem Ele nada seria possível. Deixamos um agradecimento especial à nossa orientadora pelo incentivo e pela dedicação do seu escasso tempo ao nosso projeto de pesquisa. Além do Centro Universitário de Brasília, UniCEUB, por nos proporcionar uma base teórica para a realização desse projeto. 


\section{RESUMO}

O termo abordado nesta pesquisa refere-se ao estudo da neurociência aplicada aos ambientes hospitalares, tendo a finalidade de perceber o modo em que os pacientes e funcionários reagem a esse impacto. $\mathrm{O}$ objetivo foi desenvolver uma pesquisa sobre a Neuroarquitetura para compreender como ela pode influenciar e ajudar a área hospitalar, afim de comparar com os atuais métodos construtivos e propor uma melhor solução qualitativa. Além de pesquisas voltadas para as vantagens positivas para reabilitação dos pacientes, foram realizadas pesquisas bibliográficas a respeito do tema, visitas ao Hospital Regional do Jardim Ingá, no município de Luziânia, Goiás. O hospital de referência para a pesquisa foi o Hospital Universitário de Akershus. Projetado pelo escritório CFM øller Architects, em Oslo na Noruega, localizado em um ambiente amplo e envolto por um anel com áreas verdes, utiliza-se da arquitetura vernacular usando materiais da região integrados em toda estrutura do hospital, esses materiais variam por todo o complexo criando partes individuais e que, de forma geral, continuam mantendo uma identidade arquitetônica única. Foi utilizado desta técnica nas propostas realizada, usando elementos da mesma linguagem em todos os ambientes, mantendo uma harmonia e coerência. $O$ desenvolver da criação desses espaços contém a questão da iluminação no ambiente físico hospitalar garantindo uma grande finalidade de contribuir para os ambientes humanizados. Assim como a iluminação, o uso de cores faz com que o desenvolvimento do espaço seja totalmente oportuno, como exemplo, as cores mais suáveis e que tenha uma composição harmônica. Para a utilização da Neuroarquitetura, deve ser feita com profissionais formados na área e de forma ética, pois envolve diretamente a mente humana. Sem a compreensão dos indivíduos, essa mudança na arquitetura é percebida pela liberação de substâncias químicas, neurotransmissores e principalmente pelo estado mental. E já comprovado, a própria humanização em um ambiente hospitalar é a condição imprescindível para que esses sentimentos positivos floresçam, ajudando a superar o estresse, a dor e a espera do momento da alta. Após as pesquisas, foram feitos as análises e o levantamento no hospital objeto de estudo, com as propostas. Como resultados, foi feito um fluxograma e apresentadas as propostas dos ambientes selecionados. Concluiuse que esta pesquisa é importante para planejar futuros projetos de arquitetura e que as faculdades de arquitetura e de engenharia e os profissionais já formados podem utilizar de seus benefícios. Comprovou-se que a Neuroarquitetura em um ambiente hospitalar contribui para o bem-estar do paciente e dos os usuários. Um espaço mais efetivo e salubre pode conceber influência direta para um grau profundo do organismo.

Palavras-Chave: Arquitetura. Neuroarquitetura. Ambientes Hospitalares. Projetos. 


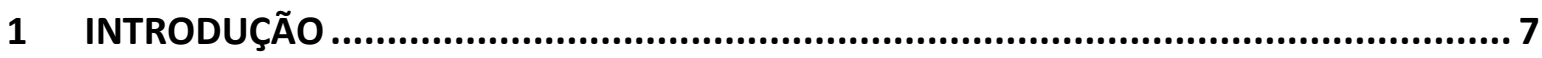

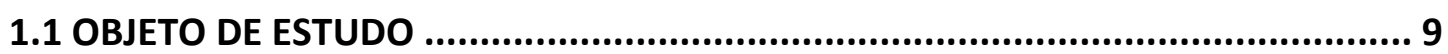

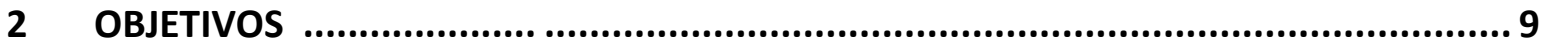

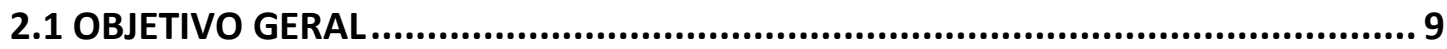

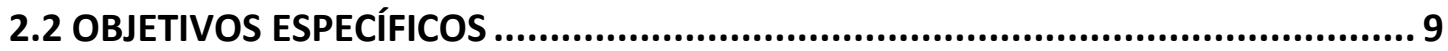

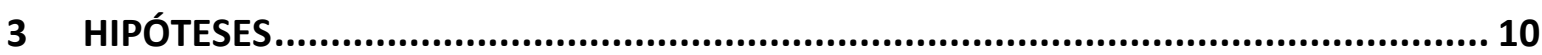

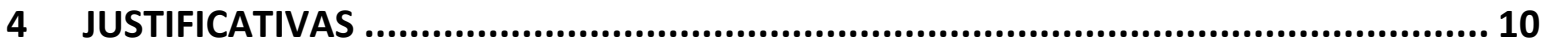

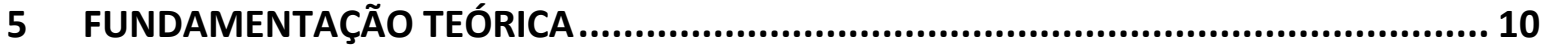

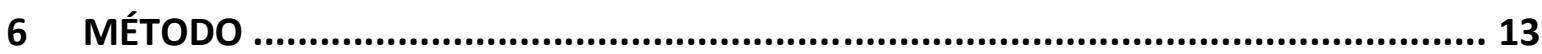

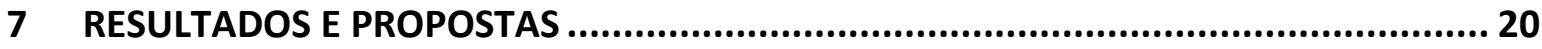

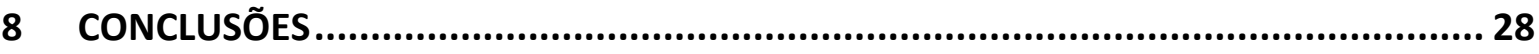

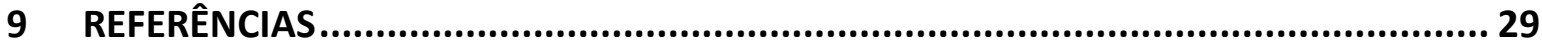




\section{INTRODUÇÃO}

É cada vez mais importante a necessidade de se identificar e diagnosticar os fatores que contribuem para o aumento da infecção hospitalar. Um dos principais impactos é o incremento das infecções e o aumento da mortalidade por possíveis enfermidades. Os impactos negativos que a contaminação causa à população levam os órgãos governamentais competentes a implementarem medidas de gerenciamento ambiental e a criarem legislação pertinente.

A falta de política de Saúde Coletiva leva ao estado de degradação do meio ambiente, que inclui o ambiente de trabalho. Neste ambiente, tanto interno quanto externo, o trabalhador está duplamente exposto. Os trabalhadores sanitários questionam a saúde afirmando que ela corresponde à definição de felicidade e que tal estado de completo bem-estar é impossível de se alcançar. Diz-se que o estado do completo bem-estar não existe, mas a saúde deve ser entendida como a busca constante de tal estado, um direito humano.

Os elementos do direito estão relacionados também ao direito ambiental. 0 homem sempre teve necessidade e direito à saúde. Mas não basta apenas dizer que todos têm direito à saúde, é indispensável que a Constituição Brasileira organize os poderes do Estado e a vida social de forma a assegurar o direito a cada pessoa. A saúde como direito humano é objeto da Organização Mundial de Saúde (OMS).

As ações sobre o meio ambiente devem ser observadas em uma escala global e faz-se necessário alavancar a mobilização entre governos e sociedade visando uma postura de co-responsabilidade em relação ao uso racional, manejo integrado e proteção sustentável dos ecossistemas. Várias instituições nacionais e internacionais hoje estão envolvidas para manter a qualidade do ar, protegendo, assim, o bem estar, a saúde humana, os animais, as plantas, os ecossistemas e os materiais. Deve-se buscar soluções para resolver os problemas mais graves relacionados à qualidade de vida e saúde ambiental, como a adoção de políticas; a preservação das funções hidrológicas, biológicas e químicas dos ecossistemas; o fortalecimento da participação da sociedade civil e dos investimentos de capacitação para qualificar essa maior participação da sociedade. E, talvez, as preocupações dos projetistas dos hospitais 
não estejam sendo consideradas na elaboração dos projetos de arquitetura hospitalar, que devem se basear em Normas de Saúde do Ministério da Saúde, da ABNT, em Leis, em Portarias e em Resoluções. Por isso, a necessidade deste estudo.

A neuroarquitetura possibilita ambientes mais humanizados, que influenciam diretamente na mente humana e podem gerar sensações de bemestar e aumentar a sensação de conforto aos usuários, sendo assim um avanço tecnológico na hora de pensar em como projetar. Um ambiente hospitalar é algo mais complexo do que pode-se imaginar, quando aplicamos a Neuroarquitetura possibilitamos um aspecto mais acolhedor gerando conforto e criando possibilidade na assistência em recuperação e tratamento dos pacientes. Além dos infermos, também influencia os profissionais que trabalham sobre pressão e estresse. Antigamente, os hospitais eram projetados para os próprios funcionários, pensando em agregar mais o lado funcional. Atualmente com a Neuroarquitetura, é possível projetar para o bem-estar do usuário, paciente, sem comprometer a funcionalidade do hospital.

Priscilla Bencke, arquiteta especializada em Projetos para Ambientes de Trabalho na escola alemã Mensch\&Büro Akademie e a única brasileira com a certificação Quality Office Consultant, realizou um estudo que faz relato sobre a utilização de elementos naturais quando aplicados em edificios hospitalres, geram benefícios para a mente humana, e de acordo com Priscilla o Brasil é um país que sofreu uma urbanização bastante acelerada e existem gerações que prezam pelo contato com a natureza e que querem estar em contato com ela, e o material ideal para se usar é a madeira, estudos realizados pela Human Spaces da psicóloga Marjut Wallenius que analisa os efeitos psicológicos que a madeira causa nas pessoas e conclui que a madeira tem um efeito psicológico sobre os seres humanos e reduz o estresse de forma semelhante à natureza.

Pode-se considerar que a Neuroarquietura se estende ainda mais, fazendo com que tudo em nossa volta, cause melhorias para nosso lado físico e psicológico. Além de todo trama em relação ao espaço, a neuroarquitetura envolve a questão da Iluminação no ambiente físico hospitalar garantido uma grande finalidade de contribuir para os ambientes humanizados. Criando um auxilio no tratamento de 
pacientes e acelerando a sua recuperação; além, da melhoria de qualidade das atividades desenvolvidas pelos profissionais de saúde.

Ainda na pesquisa estudou-se que função de uma boa iluminação em espaços hospitalares é a melhoria do estado fisiológico e psicológico dos indivíduos. A iluminação bem projetada é um ponto muito importante para os pacientes que se encontram confinados nos quartos de internação. Importante falar que não só a luz artificial é notada, mas sim a natural, que gera um grande ponto de auxílio para os arquitetos. Assim como a iluminação, o uso de cores harmônicas faz com que o desenvolvimento do espaço seja totalmente influenciado.

\subsection{OBJETO DE ESTUDO}

O objeto de estudo teve um enfoque no ambiente hospitalar, e o hospital selecionado foi o Hospital Regional do Ingá, no município de Luziânia, Goiás.

\section{OBJETIVOS}

\subsection{OBJETIVO GERAL}

Desenvolveu-se uma pesquisa sobre a Neuroarquitetura para compreender como ela pode influenciar e ajudar a área hospitalar, além de feitas comparações com os atuais métodos construtivos e propor uma melhor solução qualitativa.

\subsection{OBJETIVOS ESPECÍFICOS}

Estudou-se as vantagens que a Neuroarquitetura pode trazer para reabilitação dos pacientes. Comparou-se as diferenças que existem entre construir utilizando métodos racionais visando um melhor ambiente para funcionários e pacientes, do que construir pensando apenas em estética, estrutura e funcionalidade. 


\section{HIPÓTESES}

Supõe se que a forma que a neuroarquitetura se dispõe no ambiente, pode contribuir na evolução de um indivíduo clinicamente. A neuroarquitetura faz com que o ser humano seja capaz de produzir substâncias na qual o comportamento auxilia na recuperação do seu quadro clínico, e melhora a eficiência dos funcionários. Ao desenvolver a pesquisa, pretendemos fazer pesquisas de campos para comprovar através de entrevistas com pacientes e funcionários de um ambiente hospitalar que, a neuroarquitetura auxilia nas suas recuperações e fazem com que a produção aumente.

\section{JUSTIFICATIVAS}

A maioria das pessoas passam a maior parte do seu dia em seu local de trabalho, e o bem-estar do funcionário se torna um item indispensável para ele mesmo e para a empresa e em ambientes hospitalares a demanda de espaços calmos e aconchegantes acabam sendo uma necessidade, principalmente para quem tem que conviver com o mesmo ambiente todos os dias, como em caso de internos. A neuroarquitetura faz com que o ambiente tenha uma ergonomia adequada para o local, e com a arquitetura faz com que as pessoas se sintam bem influenciando nas emoções e nos comportamentos delas, resgatando uma lembrança, uma memória ou até mesmo um sentimento. A neuroarquitetura pode estar na iluminação, na decoração, na vegetação e até na própria estrutura. A madeira como sendo material totalmente natural, além de ter seus aspectos sensitivos, transmitindo sensações do indivíduo no ambiente, ela possui uma grande velocidade na execução da obra, e sua matéria prima é atóxica. Ao final da pesquisa, será estabelecida algumas visitas em ambientes onde a necessidade da neuroarquitetura se faz presente. Para que possamos constatar a importância e a relevância dela.

\section{FUNDAMENTAÇÃO TEÓRICA}

Historicamente, desde a era de Cristo, as leis vêm sendo implementadas. "Lei" é determinada ordenação racional visando ao bem-estar comum. A Legislação Brasileira (ou as Normas Brasileiras) relativa aos Estabelecimentos Assistenciais de Saúde (EAS) é ampla e abrangente. Entretanto, parece ser desconsiderada, como se pode constatar ao 
se analisar os estabelecimentos, em especial, com relação a projetos arquitetônicos hospitalares. A Organização Mundial de Saúde (Constituição, 1946) definiu "saúde" como o completo bem-estar físico, mental e social e não apenas como a ausência de doenças. É definida como direito e deve conter aspectos sociais e individuais.

A ANVISA, órgão regulamentador do sistema de saúde, desempenha a ação fiscalizadora quanto à adequação das condições do ambiente onde se processa a atividade e a existência de instalações e equipamentos, indispensáveis e condizentes com as suas finalidades, baseada no controle dos riscos associados. A RDC $50-M S$, de 21/02/2002, Normas para Projetos Físicos de Estabelecimentos Assistenciais de Saúde, é a mais importante referência para elaboração de projetos para EAS. Esta norma é o instrumento que as secretarias estaduais/municipais utilizam para analisar projetos de EAS a serem construídos, ampliados ou reformados.

Segundo a Resolução RDC 50 - MS, 2002, "infecção hospitalar" é qualquer infecção adquirida após a internação do paciente e que se manifesta durante a internação ou mesmo após a alta, quando puder ser relacionada com a internação ou procedimentos hospitalares. Outras foram estudadas como a NBR 9.050/2004, válida a partir de 30.06.2004, que fala sobre a cessibilidade a edificações, mobiliário, espaços e equipamentos urbanos. Ainda a Resolução RDC n. 283, de 26 de setembro de 2005, que dita sobre a necessidade de garantir à população idosa os direitos assegurados na legislação em vigor.

Dallari - SP, 1988, diz que o direito é uma prática social e uma política também. Direito é um conjunto de conhecimentos metodicamente coordenados, resultante do estudo ordenado das normas jurídicas, com o propósito de descobrir o significado objetivo das mesmas e de construir sistema jurídico.

Os filósofos Paracelso, Engels e Tocqueville (in Dallari, 1988) vêm conceituando o direito e a saúde ao longo do tempo. Segundo os trabalhos de Hipócrates, Paracelso e Engels (in Dallari, 1988), o "direito humano" é o reconhecimento da essencialidade do equilíbrio interno e do homem com o ambiente (bem-estar físico, mental e social) para a conceituação de saúde.

Outra corrente de pensamento, entretanto, evoluiu no sentido de conceituar a 
saúde como sendo a ausência de doenças. Pode-se encontrar a origem de tal corrente nos trabalhos do filósofo francês do início do século XVII, Descartes (in Dallari, 1988) que, ao identificar o corpo humano à máquina acreditou poder descobrir a "causa da conservação da saúde".

O arquiteto João Filgueiras Lima (in Toledo, 2006) diz que a arquitetura deve contribuir para a recuperação dos pacientes, e conseqüentemente, para o processo de cura. O paciente deve recuperar sua saúde em um ambiente agradável.

Barbosa e Araujo (2014) no projeto Edifícios e habitações sociais humanizados para idosos e portadores de Alzheimer lançam mão de elementos que atuem no psiquismo humano e tragam implícito a essência e noção de "lar". O uso da madeira nos corrimãos, cobertura, floreiras, portas e janelas, transmite sensação de proximidade, calor e conforto. As normas técnicas de uma arquitetura inclusiva devem estar presentes em todos os projetos de arquitetura.

Okamoto (2014) diz que o objetivo da obra é compreender como o homem de hoje vê e interpreta a realidade para então analisar seu comportamento e seus ideais. O autor analisa as funções e os direcionamentos da arquitetura moderna e questiona a mera atribuição dada a esse espaço físico de atender às necessidades básicas de trabalho, repouso, relaxamento e diversão.

Ciaco (2010) falou que a questão da humanização hospitalar parece ser temática bastante recorrente hoje, nas ciências da saúde, bem como na arquitetura e fornece subsídios para a estruturação de uma arquitetura hospitalar mais eficiente.

De Botton (2007) acredita que o ambiente afeta as pessoas de tal modo que não seria exagero dizer que a arquitetura é capaz de estragar ou melhorar a vida afetiva ou profissional de alguém. Uma de suas teses é a de que o que buscamos numa obra de arquitetura não está tão longe do que procuramos num amigo. Ao construir uma casa ou decorar um cômodo, as pessoas querem mostrar quem são, lembrar de si próprias e ter sempre em mente como elas poderiam idealmente ser. Cada obra de arquitetura expõe uma visão de felicidade.

Os autores escolhidos para serem analisados seguem uma linha de raciocínio que nos mostram a importância do assunto, como o ambiente nos molda e como nos 
sentimos intrigados diante uma obra e não conseguimos definir de onde vem esse sentimento. A neuroarquitetura contribui para o estudo das emoções em função do espaço. Diante disto:

"Temos a sensação do ambiente pelos estímulos desse meio, sem se ter consciência disso. Pela mente seletiva, diante do bombardeio de estímulos, são selecionados os aspectos de interesse ou que tenham chamado atenção, e só aí que ocorre a percepção (imagem) e a consciência (pensamento, sentimento), resultando em uma resposta que conduz a um comportamento." (OKAMOTO, 2002, p. 27)

Apresentando dessa forma como somos indiretamente influenciados sem ao menos ter consciência disso, de como a arquitetura é capaz de estragar ou melhorar a vida afetiva ou profissional de alguém. Sabendo de todo esse impacto que o edifício causa nas pessoas, ao se projetar um ambiente hospitalar também deve ter em conta algo funcional de qualidade e agilidade, para uma excelência de atendimento, e combinar os dois nem sempre é fácil. A humanização em ambientes hospitalares ajuda na melhoria do usuário, seja funcionário ou paciente (Santos, 2012). A forma com que o profissional lida com o espaço construído ou em construção faz com que haja melhorias com quem os utiliza.

"O hospital passou a ter uma função terapêutica, deixando de ser um lugar terminal para o doente, transformando-se num objeto de preocupação especial, afinal, - sucesso do tratamento, a cura, estaria diretamente relacionada ás suas propriedades." (BITTENCOURT, 1998, p.45)

\section{MÉTODO}

Foram realizadas leituras bibliográficas de trabalhos publicados e livros a respeito do tema. Após esta etapa, foram feitas visitas ao Hospital Regional do Ingá, localizado no município de Luziânia - GO, para fim de avaliação. Após a coleta de dados, iniciou-se uma comparação com os resultados obtidos do hospital visitado. A referência utilizada foi o Hospital Universitário de Akershus, um exemplo de arquitetura hospitalar, que apresenta uma visão sustentável e funcional um espaço compacto, verde e convidativo (Figuras 1 a $6)$. 
Projetado pelo escritório CFMøller Architects, em Oslo na Noruega, localizado em um ambiente amplo e envolto por um anel com áreas verdes, utiliza-se da arquitetura vernacular usando materiais da região integrados em toda estrutura do hospital, esses materiais variam por todo o complexo criando partes individuais e que, de forma geral, continuam mantendo uma identidade arquitetônica única. Esta técnica foi utilizada nas propostas, usando elementos da mesma linguagem em todos os ambientes, mantendo uma harmonia e coerência no hospital.

Sobre sua estrutura, ele possui um telhado de vidro onde a madeira é o material principal, fazendo uma ligação com todos os blocos, este material natural integrando a estrutura ao ambiente, faz com que o usuário seja o foco natural do projeto. A proposta é que seja um local de recuperação agradável e que neuroarquitetura interligada com o espaço influencie no tratamento.

O térreo do hospital possui um agregado de espelhos d'água e jardins pelos pátios, para que todos os pacientes em estado de internação tenham uma vista da janela salubre, além de luz natural e quartos ventilados, esses elementos são o segredo para um ambiente mais acolhedor e agradável.

O hospital contém uma coleção de obra de artes, atualmente com doze, todas elas feitas unicamente para o Hospital, além das doze, desenhos, pinturas e fotografias são adicionadas pelos corredores.

As obras de arte têm o intuito de melhorar a comunicação e interação entre a função, arte e arquitetura do espaço, além de influenciar no processo de tratamento causando uma sensação de harmonia, toda essa experiencia ligada pelos neurotransmissores da mente. 
Figura 1: Vista de cima do Hospital Universitário Akershus.

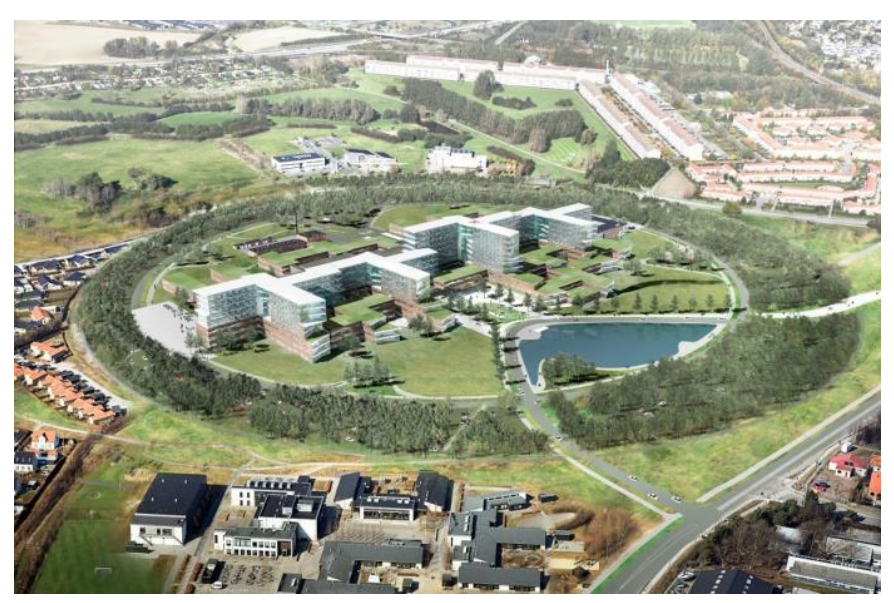

Fonte: Cfmolle - arquitetos.

Disponível em: https://www.cfmoller.com/p/Akershus-University-Hospital-New-Ahus-i269.html Acesso em ago. 2020.

Figura 2: Vista dos blocos hospitalares.

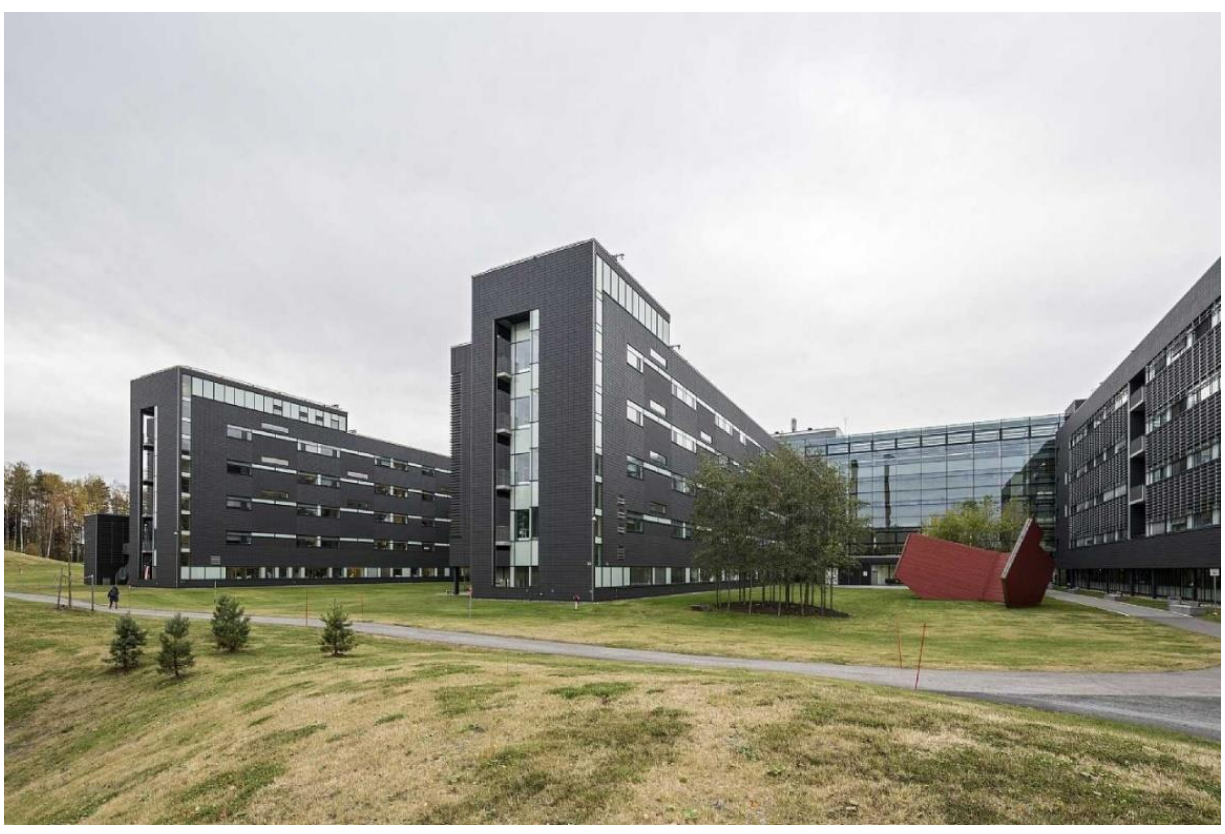

Fonte: Cfmolle - arquitetos

Disponível em: https://www.cfmoller.com/p/Akershus-University-Hospital-New-Ahus-i269.html Acesso em ago. 2020. 
Figura 3: Cinturão verde em volta do Hospital Universitário de Akershus.

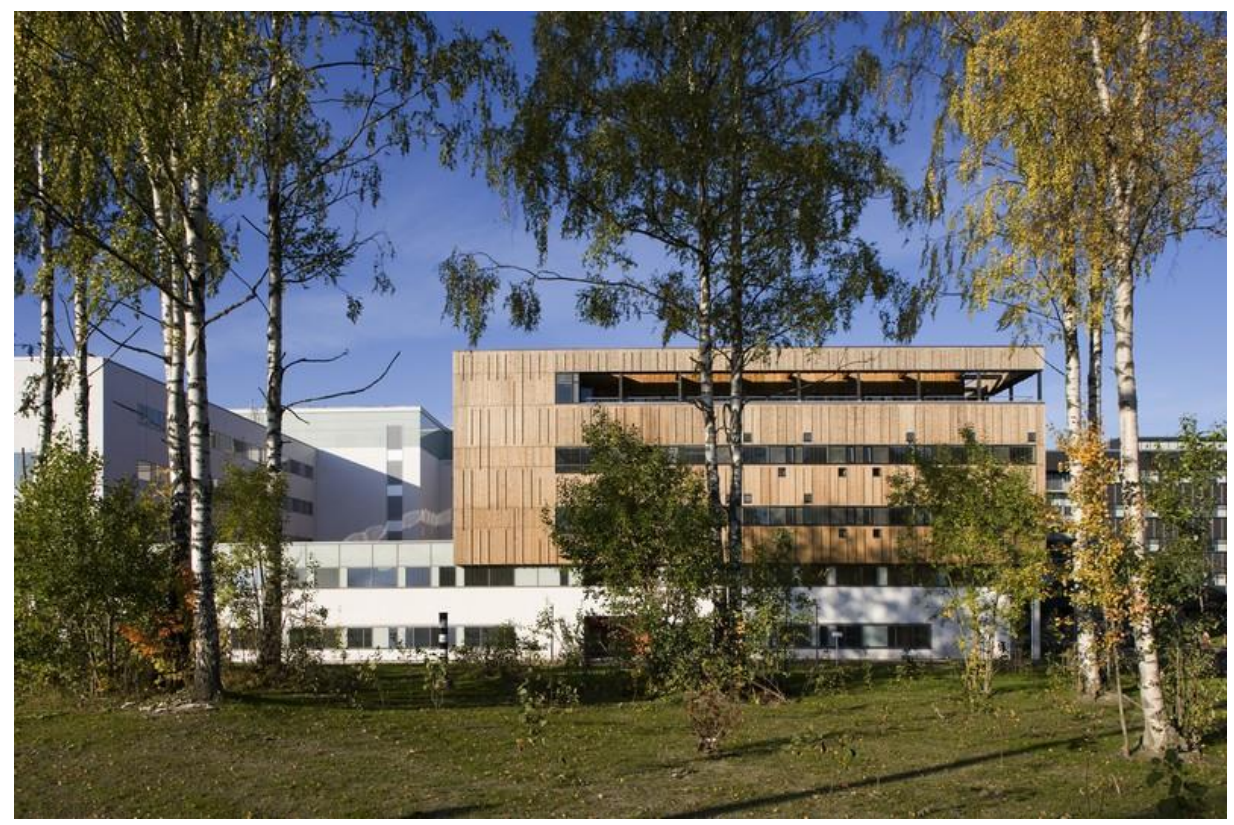

Fonte: Cfmolle - arquitetos

Disponível em: https://www.cfmoller.com/p/Akershus-University-Hospital-New-Ahus-i269.html

Acesso em ago. 2020.

Figura 4: Renderização dos espelhos d'água do Hospital Universitário de Akershus.

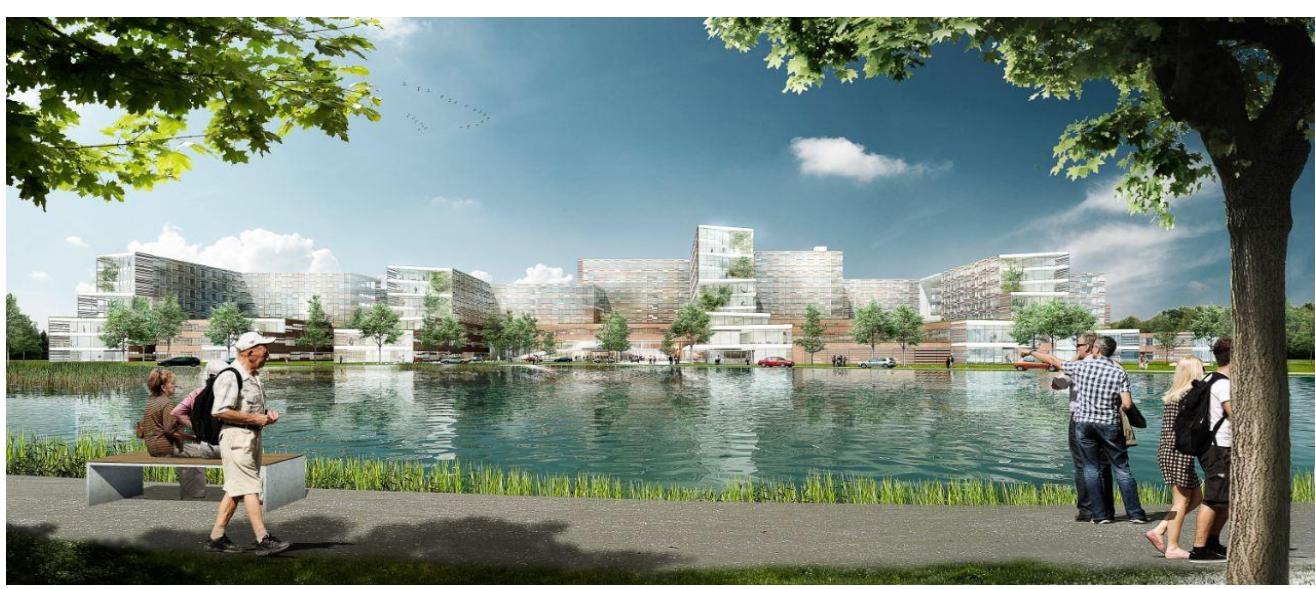

Fonte: Cfmolle - arquitetos

Disponível em: https://www.cfmoller.com/p/Akershus-University-Hospital-New-Ahus-i269.html Acesso em ago. 2020. 
Figura 5: Imagem externa do pátio no Hospital Universitário de Akershus.

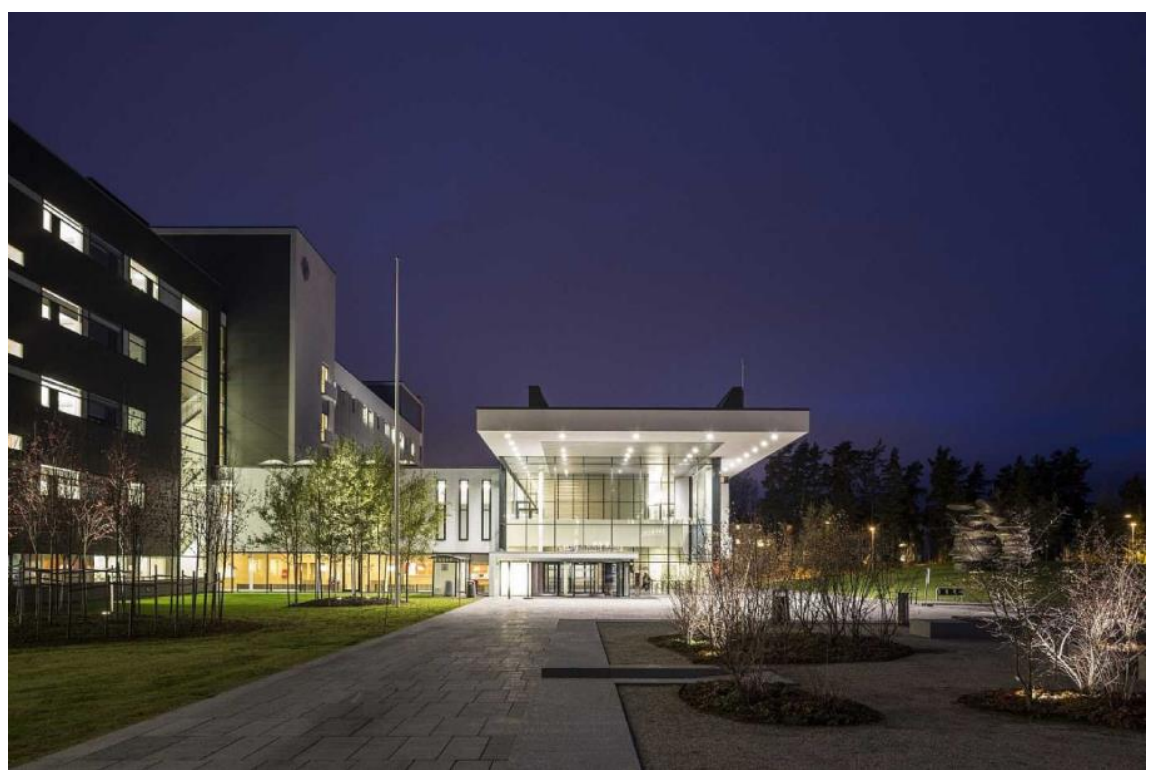

Fonte: Cfmolle - arquitetos

Disponível em: https://www.cfmoller.com/p/Akershus-University-Hospital-New-Ahus-i269.html Acesso em ago. 2020.

Figura 6: Pátio interno utilização da madeira no Hospital Universitário de Akershus.

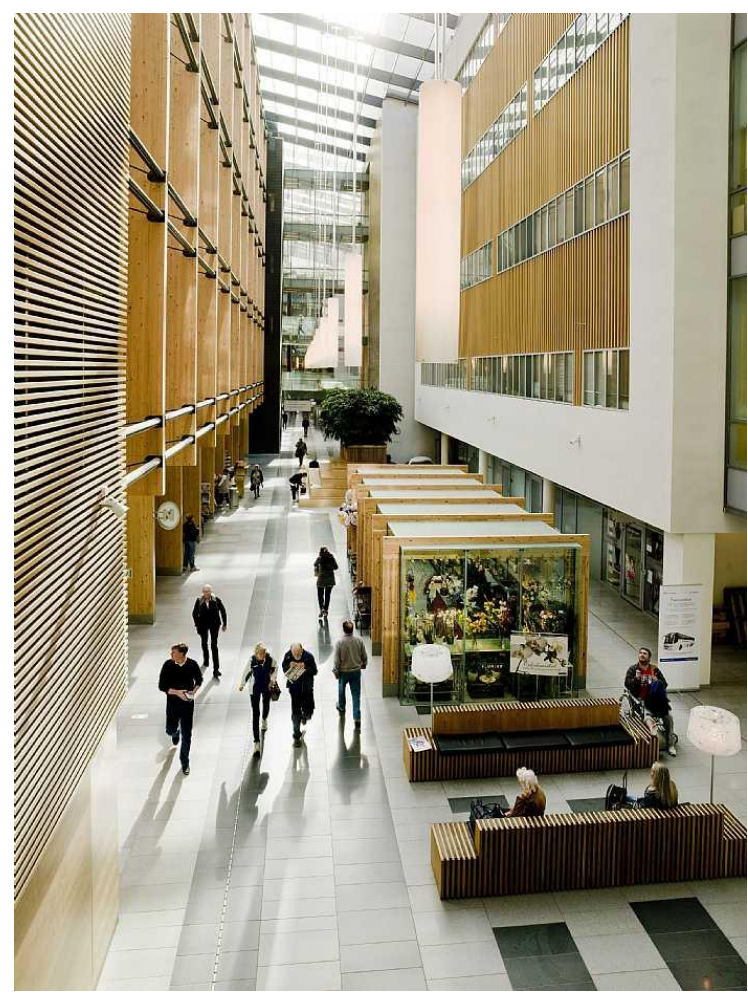

Fonte: Cfmolle - arquitetos.

Disponível em: https://www.cfmoller.com/p/Akershus-University-Hospital-New-Ahus-i269.html Acesso em ago. 2020. 
Foram utilizados alguns elementos de estudo, como a base teórica em livros, a utilização de softwares de modelagem 3D, como o SketChup e o Lumion, afim de fazer as comparações com os ambientes existente e o previsto aplicando o estudo da Neuroarquitetura.

O hospital em análise, como comentado no texto acima, encontra-se no município de Luziânia-GO, cerca de 50km da capital federal. Esse hospital de início foi inaugurado para utilização de UPA (Unidade de Pronto Atendimento), porém, com a precariedade da saúde pública no município, foi totalmente configurado para funcionar um hospital da região.

Atualmente, o Hospital Regional do Jardim Ingá, é composto por salas de cirurgia de grande e pequeno porte, salas de internação, salas de vacinas e consultórios. Além da ala laboratorial e da maternidade. O hospital consegue dar assistência a UPA do Jardim do Ingá, por conta de suas instalações serem mais atuais, com isso a funcionalidade fica mais rápida.

Figura 7: Localização HRJI em Luziânia - GO

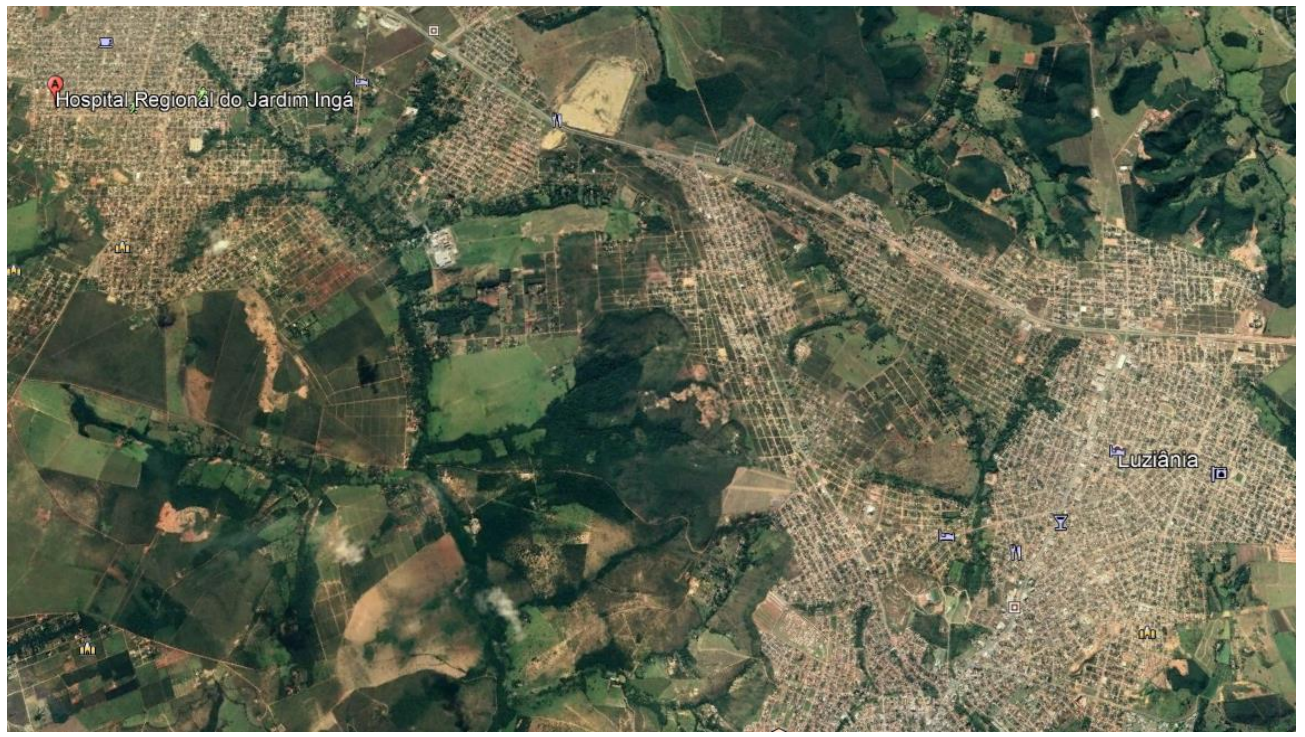

Fonte: Google Maps

Disponível em: https://www.google.com.br/maps

Acesso em ago. 2020. 
Figura 8: Rota Luziânia - Centro - Hospital Regional do Jardim Ingá - distância 18km.

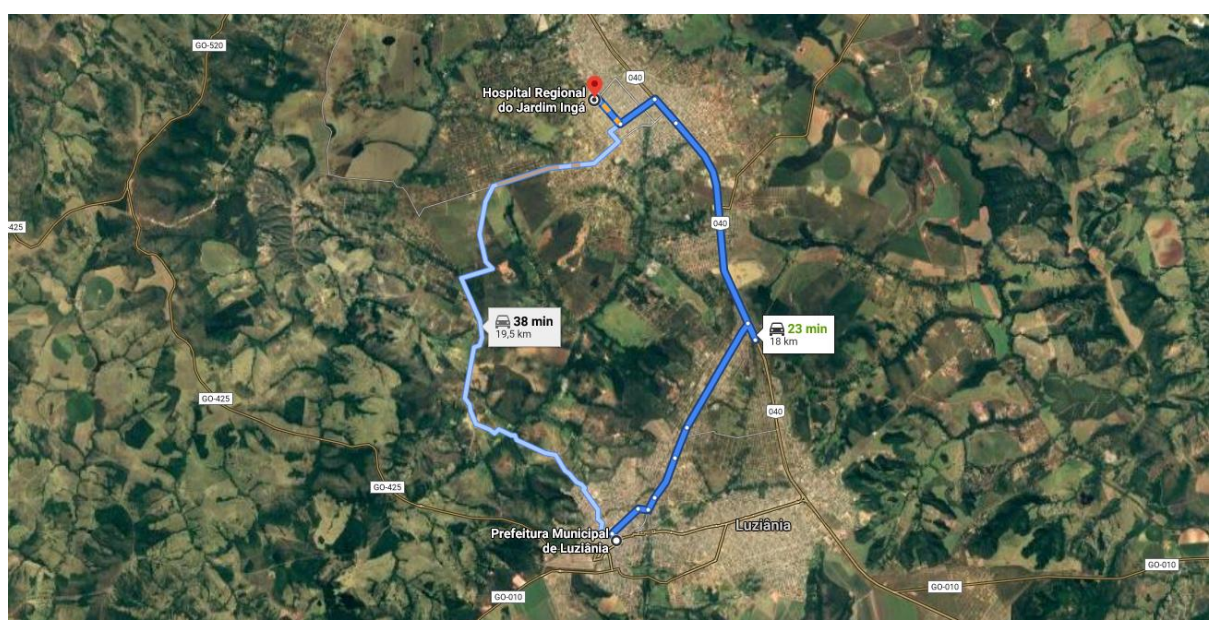

Fonte: Google Maps

Disponível em: https://www.google.com.br/maps

Acesso em ago. 2020.

Figura 9: Fachada Principal do Hospital Regional do Jardim Ingá.

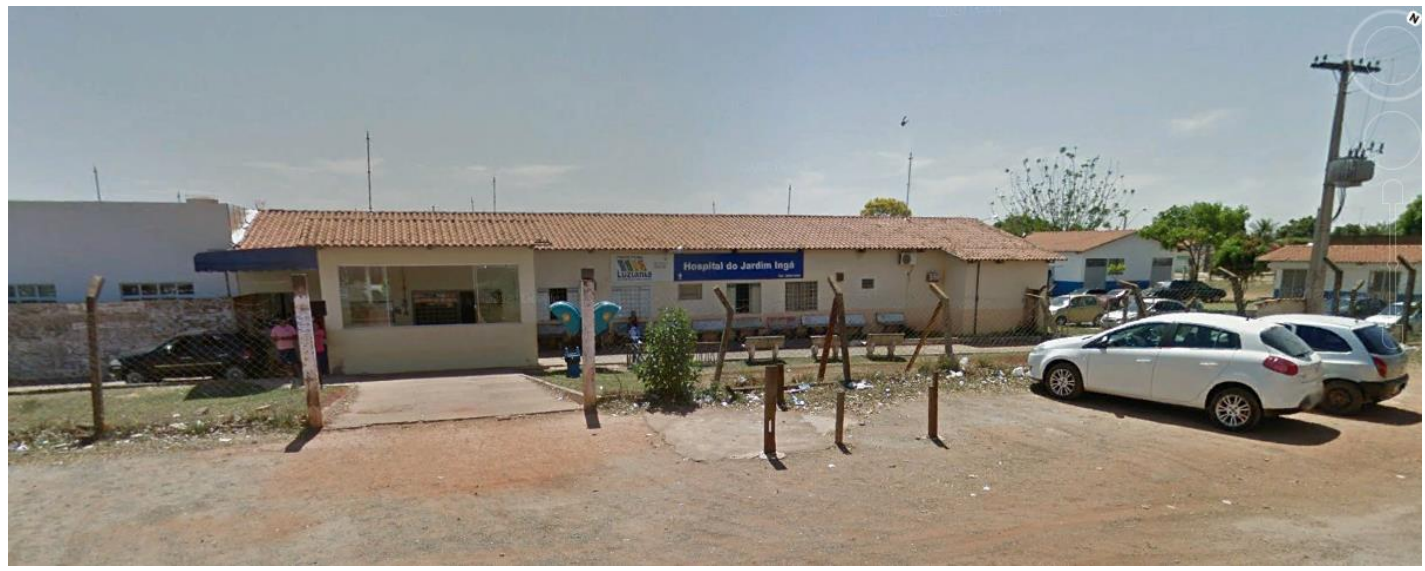

Fonte: Google Earth

Disponível em: Google Earth

Acesso em ago. 2020. 
Figura 10: Fachada Lateral Direita do Hospital Regional do Jardim Ingá.

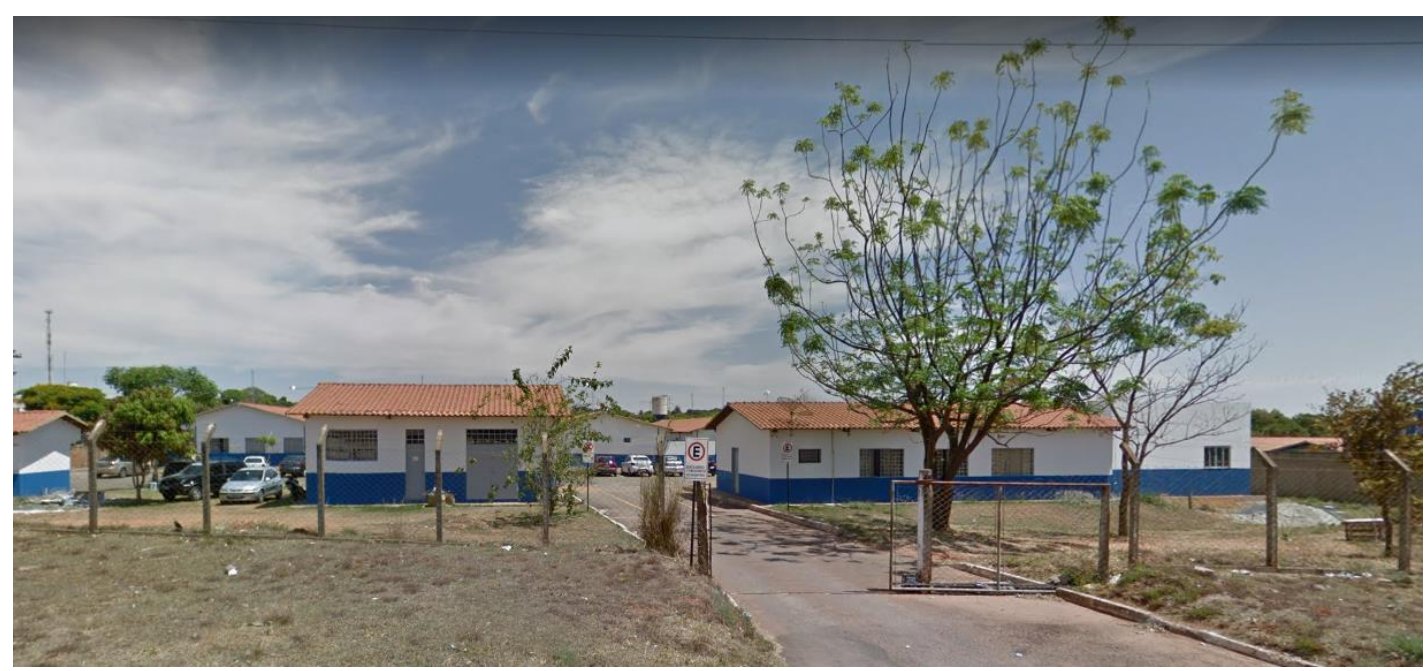

Fonte: Google Maps

Disponivel em: https://www.google.com.br/maps

Acesso em ago. 2020.

Figura 11: Fachada Lateral Direita do Hospital Regional do Jardim Ingá.

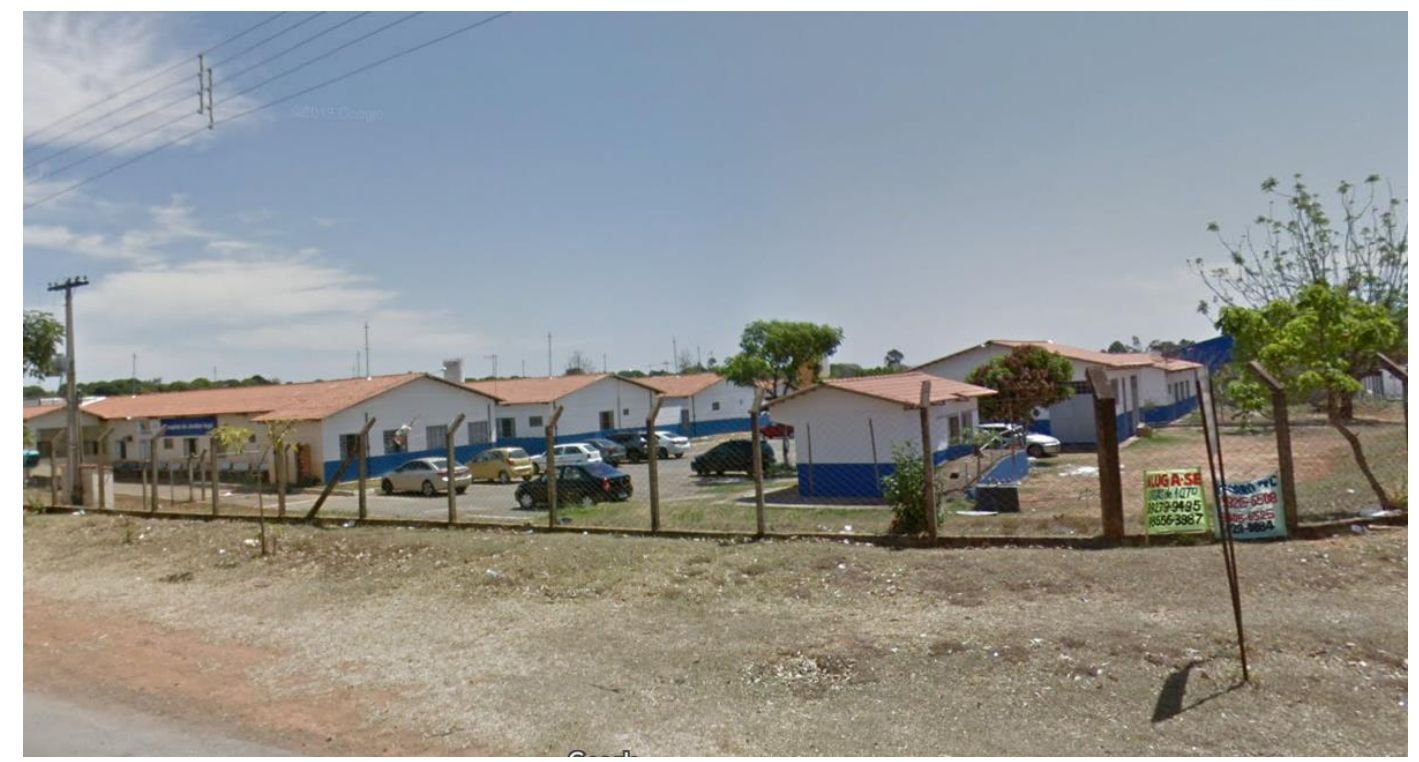

Fonte: Google Maps

Disponível em: https://www.google.com.br/maps

Acesso em ago. 2020.

\section{RESULTADOS E PROPOSTAS}

Por ser uma edificação antiga, os arquivos contendo os desenhos técnicos não foram encontrados. Sendo assim, a compreensão do espaço foi definida por um fluxograma, mostrado na Figura 12. 
Figura 12: Fluxograma.

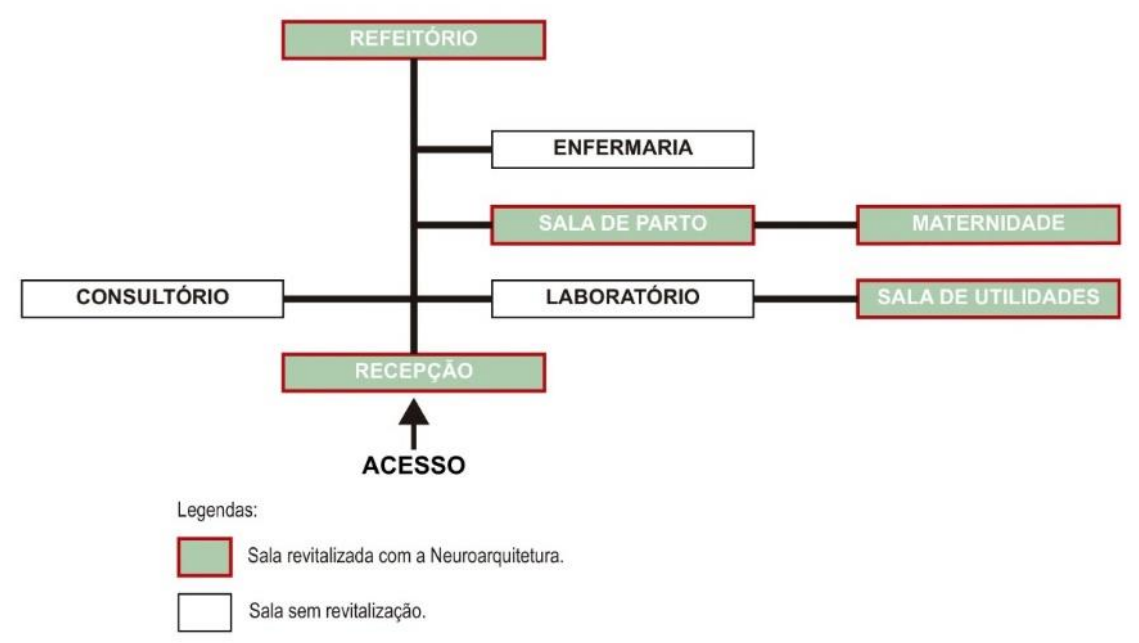

Fonte: Acervo pessoal.

A proposta foi fazer a revitalização dos espaços no hospital em estudo (Figura 13). Iniciou-se pelo departamento infantil, na área de maternidade. Por se tratar de um hospital público onde as verbas são limitadas, procurou-se fazer uma reconstrução utilizando materiais de fácil aplicação e baixo custo. As cores possuem diversas funções e podem influenciar as nossas emoções, com isso o uso de cores harmônicas fez com que o ambiente se tornasse mais salubre e criativo. A utilização de tons pastéis, para compor um visual mais aconchegante e não tão pesado visualmente, quadros e obras de arte trazem alegria ao ambiente e desperta o interesse dos pacientes.

As áreas verdes proporcionam uma sensação doméstica e agem indiretamente na mente, trazendo sensações de calmaria. Por isso a importância de elementos naturais nos ambientes hospitalares para diminuir os sentimentos de estresse e angústia. A iluminação artificial colocada em "zigue-zague" é uma estratégia para que o paciente que esteja situado em cima de uma maca, não sofra diretamente com a luz em seu rosto, causando um desconforto físico, além de visual. Vale ressaltar que a iluminação natural, deverá sempre estar presente de alguma forma no espaço a fim de melhorar a qualidade física do espaço (Figura 14). 
Figura 13: Imagens atuais da ala da maternidade do Hospital Regional do Jardim Ingá.

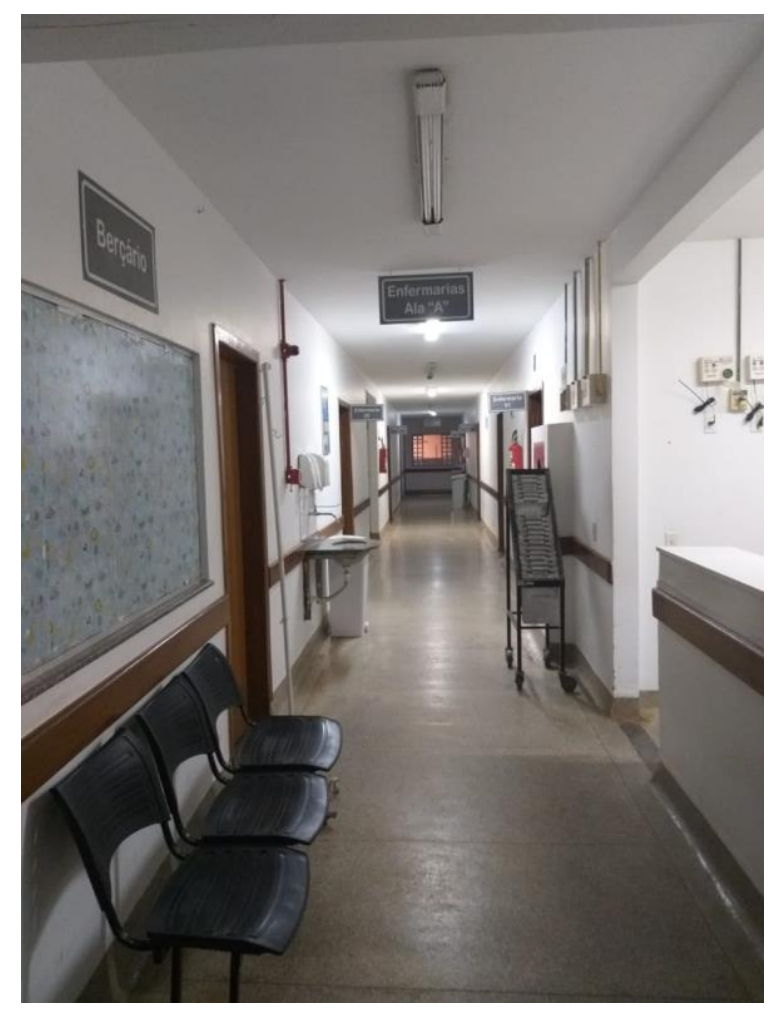

Fonte: Acervo pessoal.

Figura 14: Imagem renderizada com a aplicação da neuroarquitetura na ala da maternidade do Hospital Regional do Jardim Ingá, em Luziânia-Go.

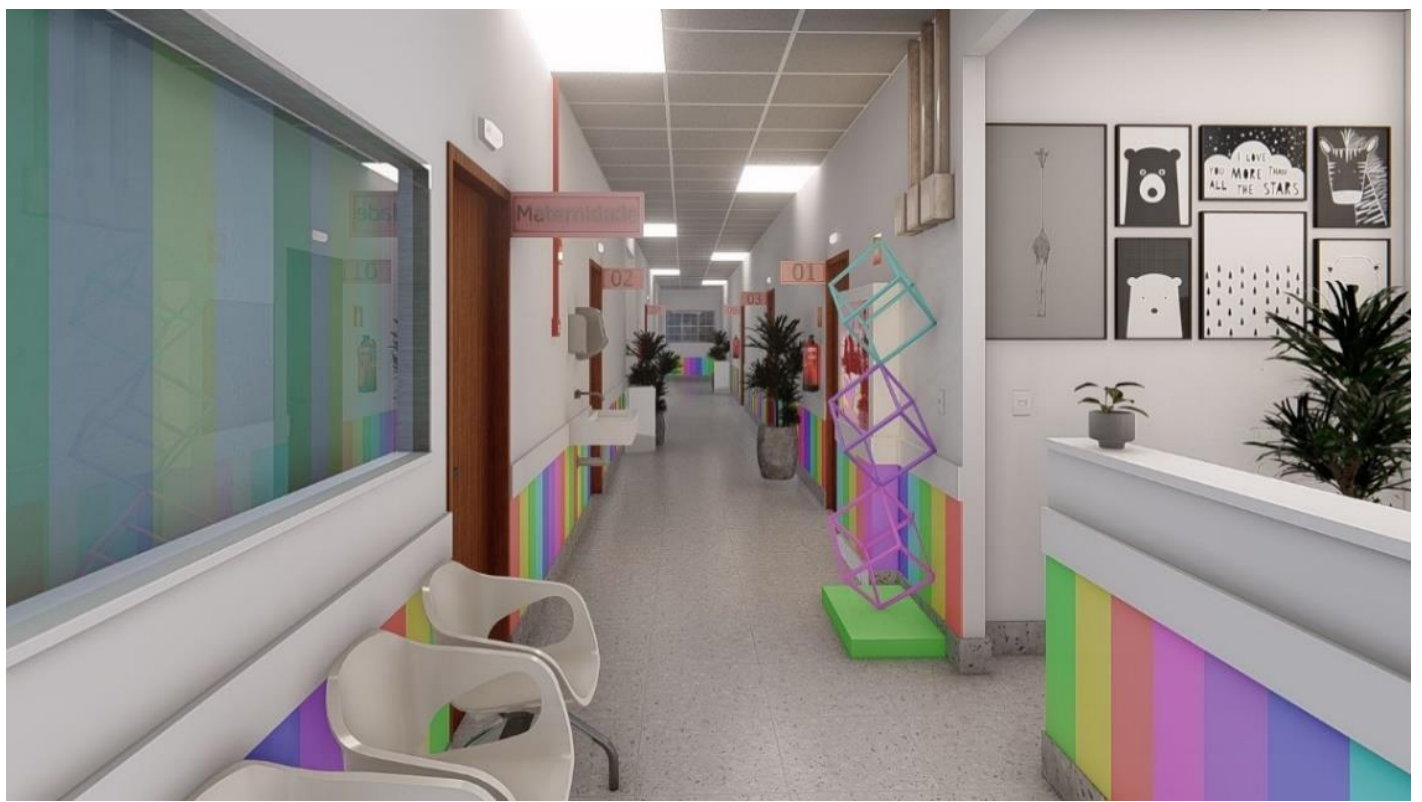

Fonte: Elaborada pelos autores.

Se tratando do mesmo ambiente infantil (Figura 15), seleciona-se a sala de parto, onde acontece o nascimento dos bebês. Atualmente, pode-se perceber uma área onde 
não há muito o que se aconchegar. A sala de parto sempre é um espaço onde a paciente chega e vai embora rapidamente, ou seja, não é um espaço que contém uma permanência de pessoas. Porém, no desenvolver do estudo, foi notado que as mulheres que chegam em salas mais aconchegantes e salubres, conseguem ter um parto mais tranquilo, pois as cores influenciam diretamente na mente humana, a fazendo produzir hormônios que causam mais calmaria. A neuroarquitetura foi instalada na forma de um bom revestimento, onde não vá trazer complicações visuais para os servidores, porém são cores harmônicas que agregam no sentido de acalmar a paciente em um momento importante de sua vida (Figura 16).

Figura 15: Imagens atuais da sala de parto do Hospital Regional do Jardim Ingá.

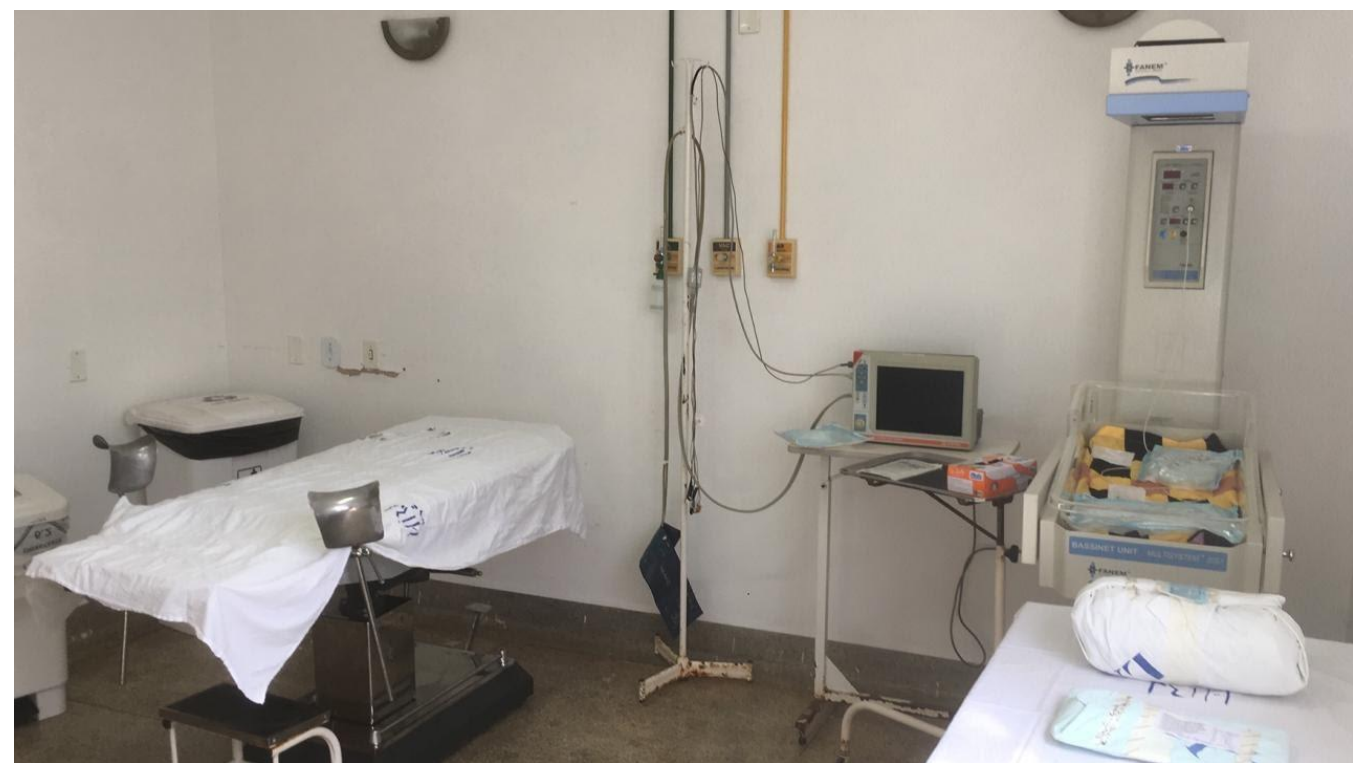

Fonte: Acervo pessoal. 
Figura 16: Imagem renderizada sobre a aplicação da neuroarquitetura na ala de maternidade/sala de parto do Hospital Regional do Jardim Ingá.

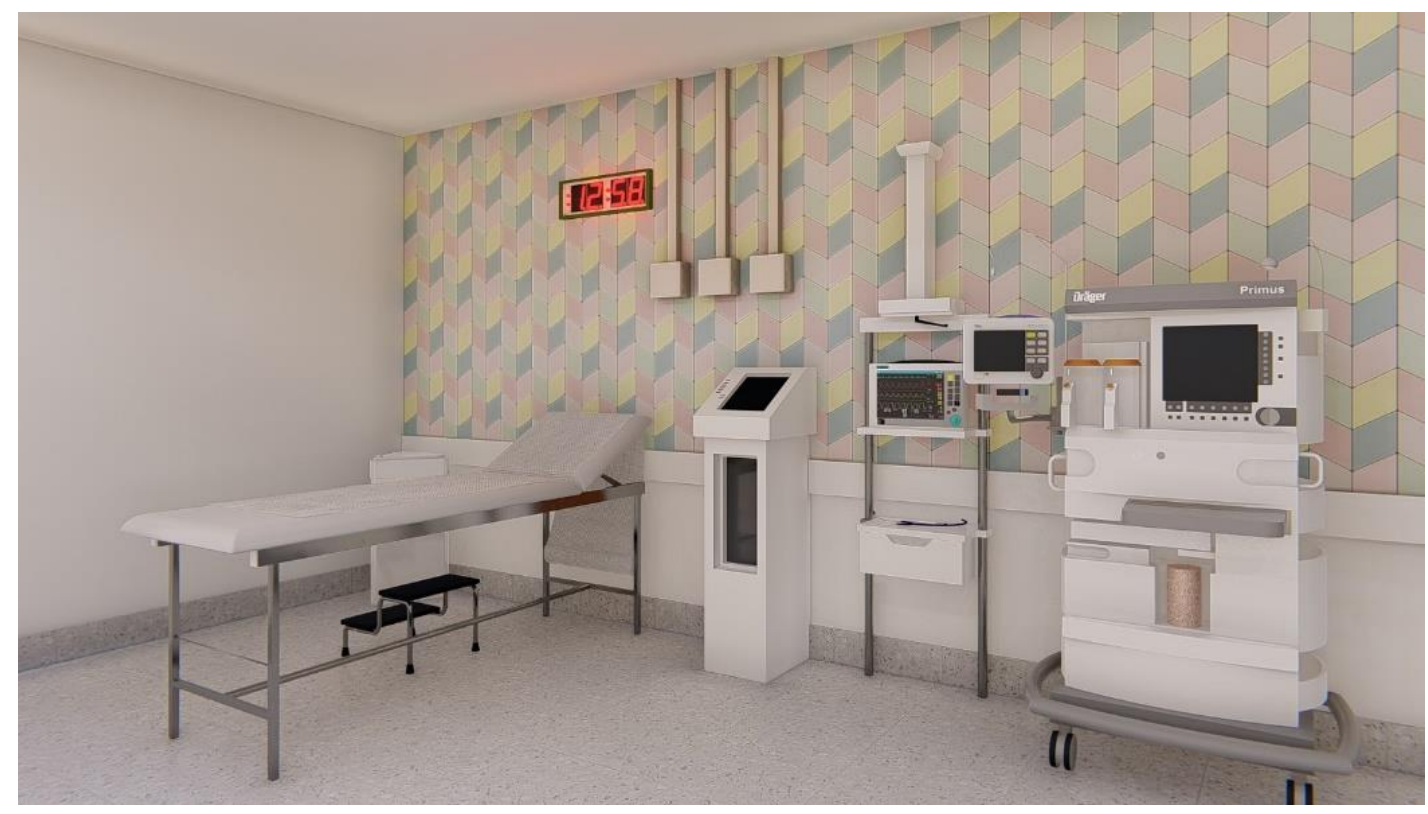

Fonte: Elaborada pelos autores.

A sala de utilidades é um ambiente destinado à limpeza, desinfecção e guarda dos materiais e roupas utilizados na assistência ao paciente. Deve conter uma pia, esguicho de lavagem e uma pia de despejo com uma válvula de descarga que desce diretamente para uma tubulação de esgoto. Na imagem representada a seguir, pode-se perceber que há uma carência de ducha higiênica, e que o expurgo está exposto de maneira incorreta. A forma incorreta da utilização dos espaços mais funcionais no dentro dos ambientes hospitalares causam uma série de desconfortos para os funcionários que a utilizam diariamente (Figura 17). Analisando uma melhor forma de adaptação do espaço, será necessário colocar um fechamento de toda parte inferior, com portas, para que os resíduos não sejam vazados e fiquem sem proteção.

A necessidade de realocar o expurgo com uma distância maior da pia de limpeza, por questões higiênicas. Ao relocar os itens, foi instalado um tampo de aço inox, pois a superfície do aço inox não é porosa, ou seja, bactérias, vírus e manchas não podem adentrar, da mesma forma a utilização de produtos químicos agressivos, ele não é afetado (Figuras 18 e 19). 
Figura 17: Imagens atuais da sala de utilidades do Hospital Regional do Jardim do Ingá.

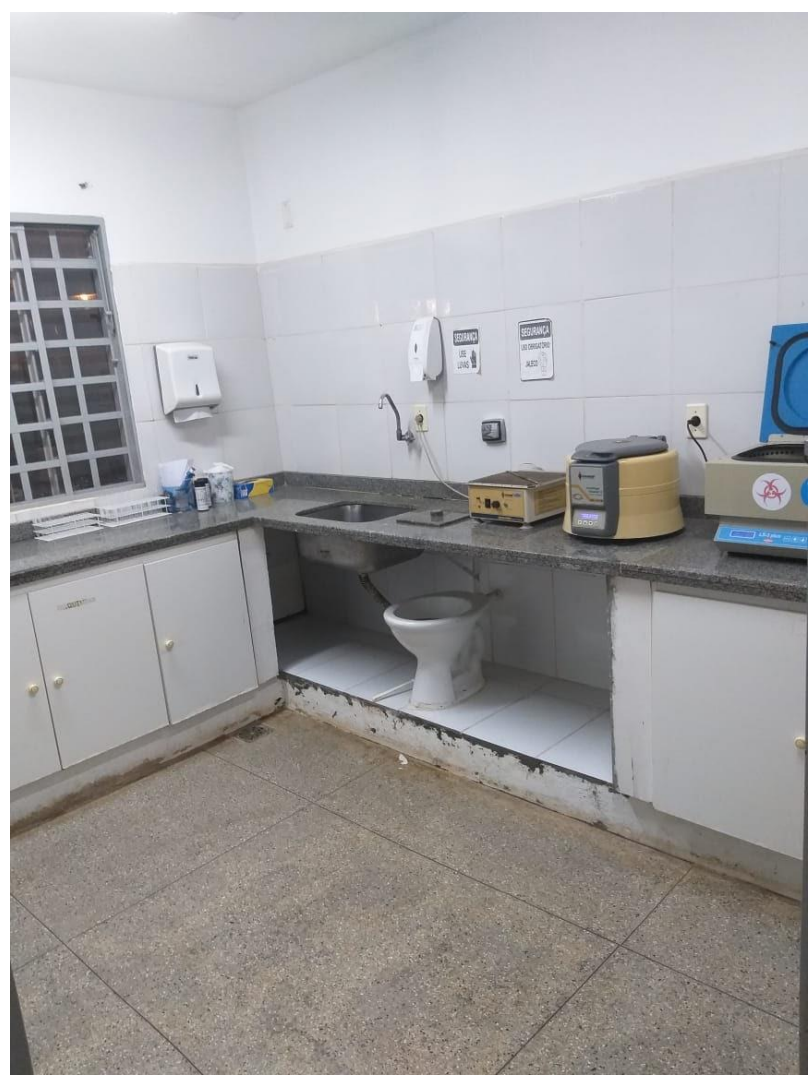

Fonte: Acervo pessoal.

Figura 18: Imagem renderizada sobre a aplicação da neuroarquitetura na sala de utilidades do Hospital Regional do Jardim Ingá.

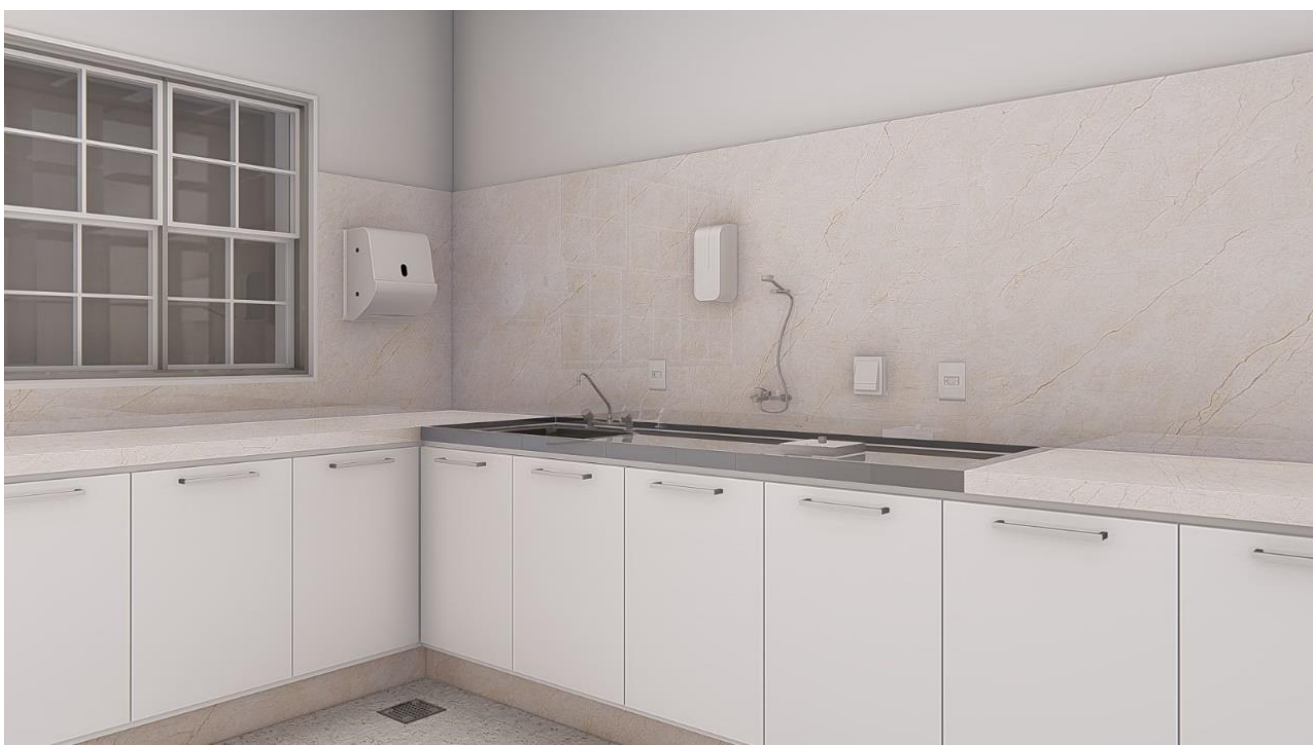

Fonte: Elaborada pelos autores. 
Figura 19: Imagem renderizada sobre a aplicação da neuroarquitetura na sala de expurgo do Hospital Regional do Jardim Ingá.

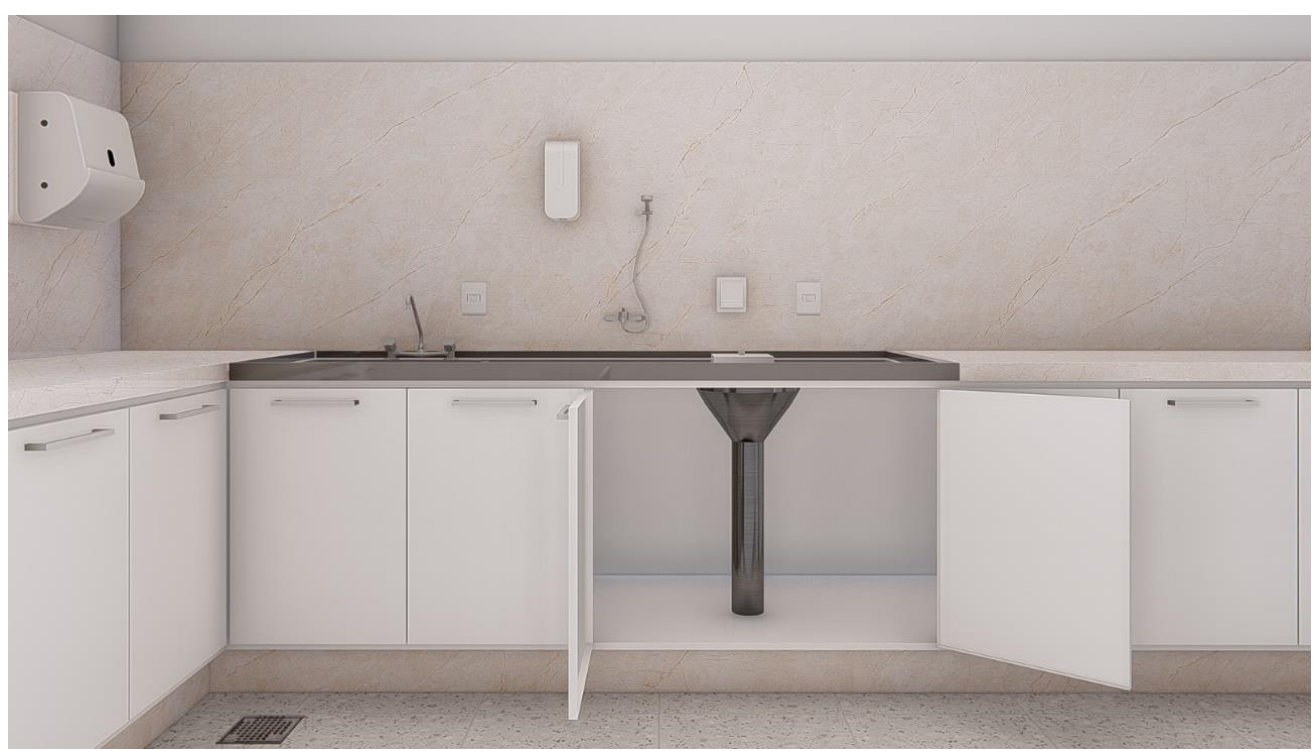

Fonte: Elaborada pelos autores.

Continuando nos ambientes únicos para funcionários e prestadores de serviços hospitalares, no refeitório também foram previstas algumas mudanças. Atualmente, encontra-se com os equipamentos degradados e sem espaço para a limpeza e armazenamento de materiais (Figura 20). Com a aplicação da Neuroarquitetura, foi instalada uma bancada de madeira, plantas e harmonizações verdes para trazer a lembrança dos elementos naturais (Figura 21).

Figura 20: Imagens atuais da sala do refeitório do Hospital Regional do Jardim Ingá.

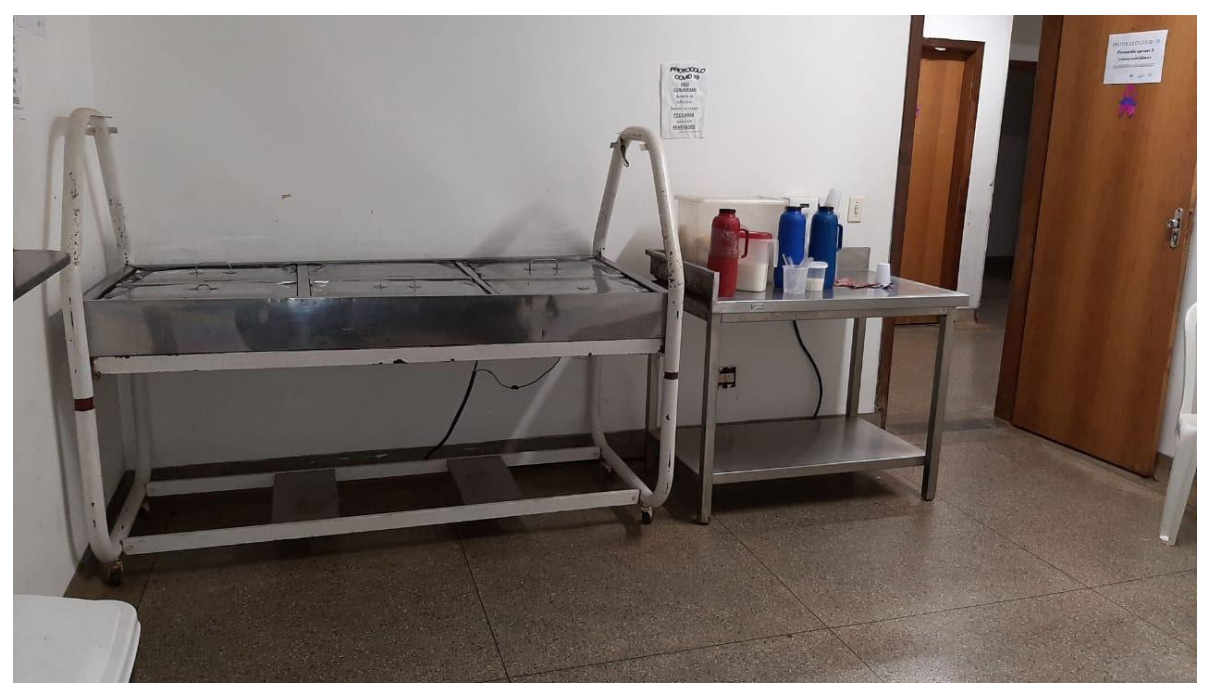

Fonte: Acervo pessoal. 
Figura 21: Imagem renderizada sobre a aplicação da neuroarquitetura no refeitório do Hospital Regional do Jardim Ingá.

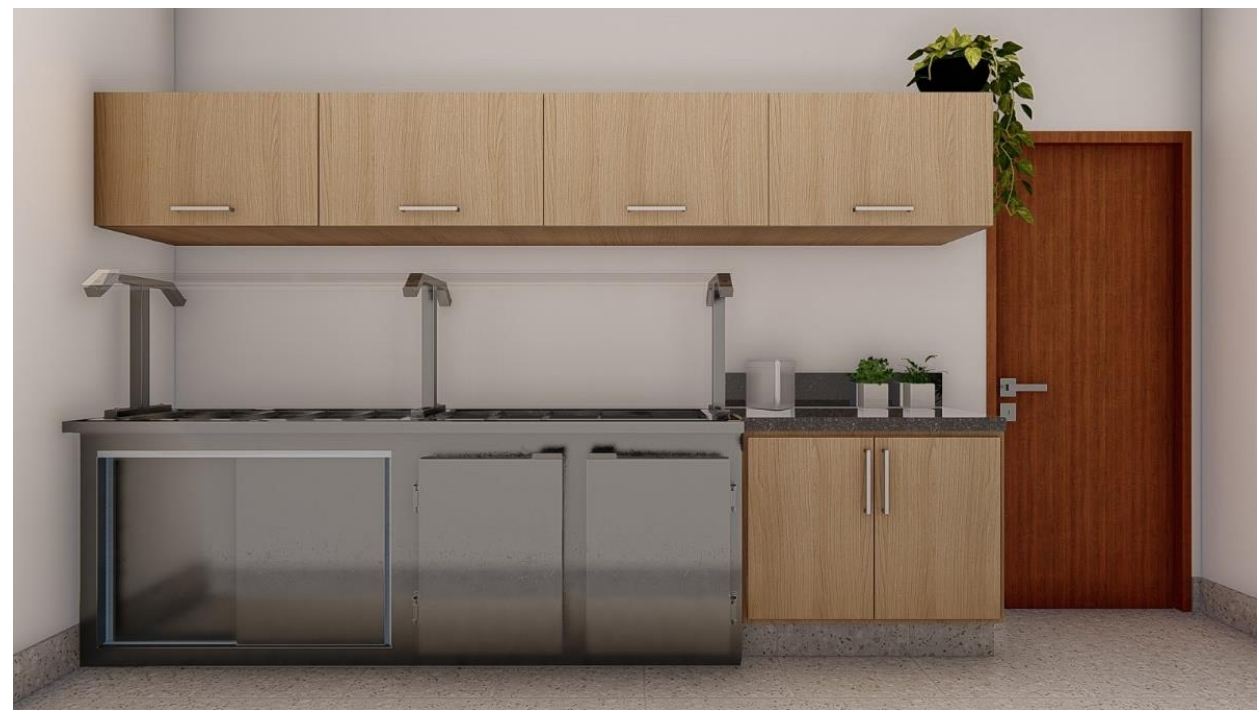

Fonte: Elaborada pelos autores.

Fazendo o estudo do espaço onde há mais aglomeração, a recepção atual conta com um espaço sem cor, onde a humanização não foi implantada. No momento da chegada ao hospital, o sentimento que mais aparece nos pacientes é a preocupação, angústia e a dor (Figura 22). Nesse estudo, foi necessário incluir uma parede na tonalidade esverdeada para que trouxesse a sensação de calmaria, fazendo com que o paciente não fique preso apenas ao branco em sua volta. Houve a inclusão dos elementos naturais, como as plantas, que fazem com que o espaço fique mais aconchegante (Figura 23).

Figura 22: Imagens atuais da sala da recepção do Hospital Regional do Jardim do Ingá.

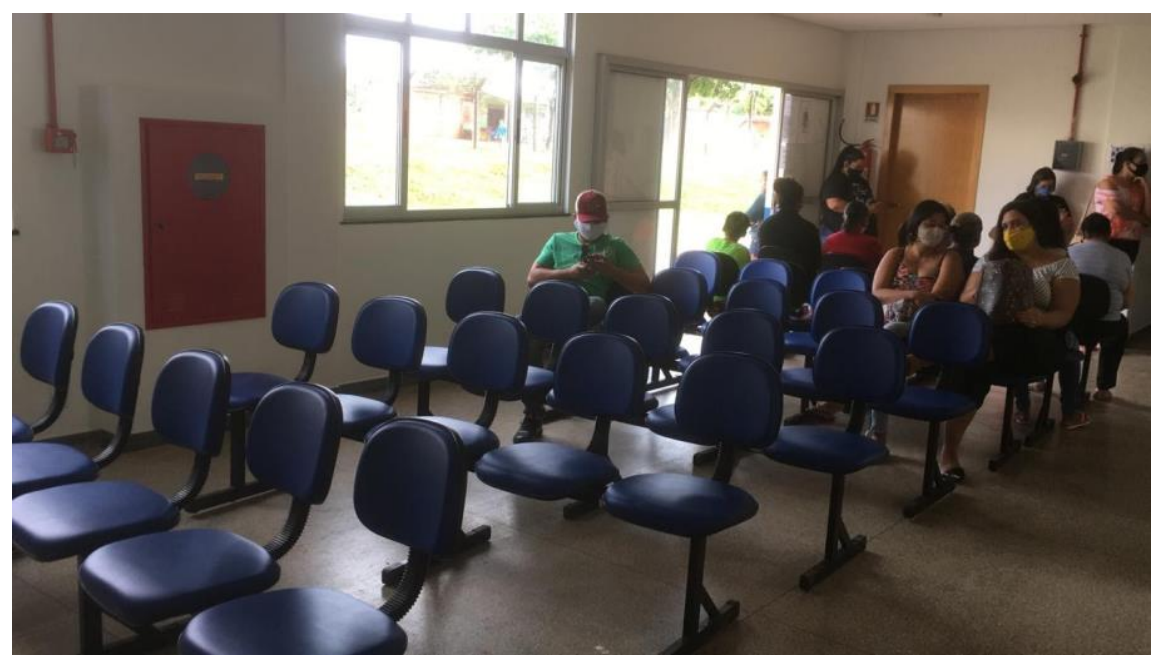

Fonte: Acervo pessoal 
Figura 23: Imagem renderizada sobre a aplicação da neuroarquitetura na recepção do Hospital Regional do Jardim Ingá.

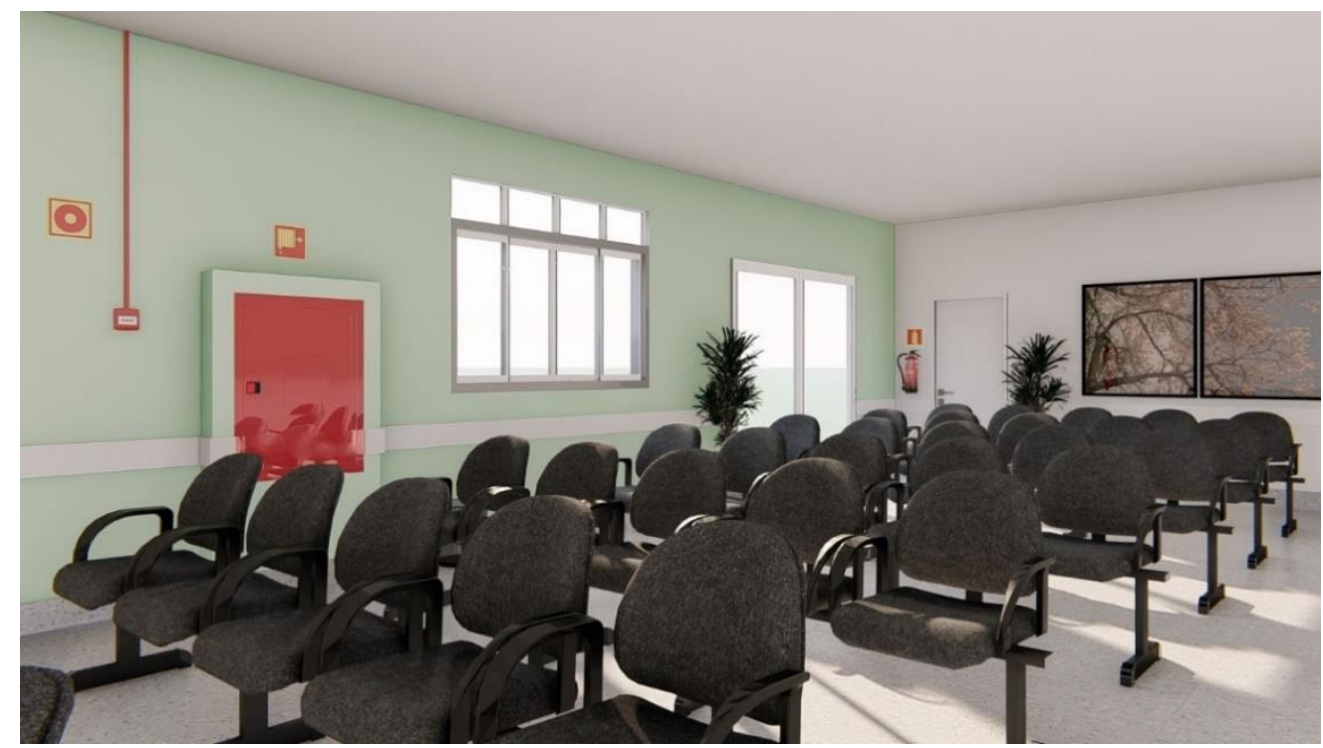

Fonte: Elaborada pelos autores.

\section{CONCLUSÕES}

Concluiu-se que esta pesquisa é importante para planejar futuros projetos de arquitetura e que as faculdades de arquitetura e de engenharia e os profissionais já formados podem utilizar de seus benefícios. Quando bem projetados e com foco na humanização contribuem para a melhoria do estado humano dentro do ambiente hospitalar, fazendo assim uma grande diferença no tratamento do paciente.

Nos últimos anos, os ambientes de saúde se depararam com novos desafios e passaram a ter uma maior preocupação com a experiência do paciente como um todo. Com isso, o setor da saúde teve que pesquisar soluções adequadas em relação psicológica dos usuários com o espaço em que os acolhe. Esses edifícios projetados com a atuação da Neuroarquitetura estão, além de simples questões como a estética e a funcionalidade, sim focando nos impactos gerados no inconsciente. Dessa forma, a relação dos usuários com os edifícios vai ficar ainda mais afetiva.

O grande objetivo da Neuroarquitetura aplicada em ambientes hospitalares é justamente minimizar o estado de preocupação que surge com a doença e a hospitalização, fazendo com que haja uma estimulação de criatividade e da autoestima, amenizar a tensão, diminuir o estresse que é causado pelo ambiente hospitalar por um 
todo, além de incentivar o diálogo. Sendo assim, contribui para a melhora do acolhimento e o relacionamento dos usuários.

O principal resultado é o fortalecimento dos vínculos e uma comunicação mais afetiva entre profissionais da saúde, pacientes e acompanhantes, o que sempre favorece a empatia em suas relações. O hospital é um ambiente no qual se defrontam interesses potencialmente conflitantes, por isso, a missão dos arquitetos é tão relevante. Dessa forma, a experiência mostra que um espaço concebido para estimular a atenção dos médicos pode não favorecer o interesse mais imediato dos pacientes, que é o repouso e a boa recuperação. O desafio dos arquitetos é procurar balancear essa equação levando em consideração todo o conjunto de necessidades relativas a usuários e profissionais que fazem, cada um deles, um uso muito próprio do espaço construído. Por fim, não se trata de conceber ambientes com um aspecto visualmente confortável e sim de desenvolver dentro da mente humana, uma capacidade de melhoria para os usuários envolvidos no espaço.

\section{REFERÊNCIAS}

BARBOSA, S. B. e ARAUJO, E. P. Edifícios e habitações sociais humanizados para idosos e portadores de Alzheimer. PIBIC, 2014. Curso de Arquitetura e Urbanismo, FATECS, UniCEUB.

BITTENCOURT, Tânia. Arquitetura Sanatorial. São José dos Campos, 1998. TMM Bittencourt.

BOTTON, Alain. A arquitetura da felicidade. Ed. Rocco. São Paulo, 2007.

DALLARI, S. O Direito à Saúde. Revista Saúde Pública. São Paulo, v. 22, n. 1, p. 57-63, 1988.

DESCARTES, R. Discurso sobre o método. Rio de Janeiro, Simões, 1952.

$\mathrm{CIACO}$, Ricardo José Alexandre Simon. A arquitetura no processo de humanização dos ambientes hospitalares. Dissertação de Mestrado. Universidade de São Paulo - USP, Escola de Engenharia de São Carlos. Área do Conhecimento Arquitetura, Urbanismo e Tecnologia. São Paulo, 2010.

OKAMOTO, Jun. Percepção Ambiental e Comportamento: visão holística na Arquitetura e na comunicação. Coleção Academack. Ed. Mackenzie. 3.a ed. São Paulo, 2014.

PARACELSUS. On miner's sickness and other miner's diseases. In: DALLARI. Four teratises of Theuphrastus von Hohenheim called PARACELSUS. Baltimore, Johns Hopkins Press, 1941. p. 43-126.

SANTOS, Mauro e BURSZTYN, Ivani. Saúde e Arquitetura - Caminhos para a humanização dos ambientes hospitalares. Rio de Janeiro: Ed. Senac Rio. 1.a Ed., 2004.

TOLEDO, L. C. Feitos para curar: arquitetura hospitalar e processo projetual no Brasil. Rio 
de Janeiro: ABDEH, 2006.

\section{SITES}

Desigualdade Social e Saúde entre idosos. Rio de Janeiro, 2003. Disponível http://www.scielosp.org/pdf/csp/v19n3/15878.pdf. Acesso 26/out/2019.

NUPHEA - Núcleo de Pesquisa e Estudos Hospital Arquitetura. São Paulo, 2010.

Disponível http://www.hospitalararquitetura.com.br. Acesso 03/maio/2020.

Secretaria de Habitação do Governo do Estado de São Paulo. São Paulo, 2009.

Disponível http://habitacao.sp.gov.br/programashabitacionais/programas-

secretaria-da=habitacao/programa-viladignidade.asp. Acesso 18/ago/2020.

https://www.cfmoller.com/p/Akershus-University-Hospital-New-Ahus-i269.html

\section{NORMAS, RESOLUÇÕES E LEIS}

ANVISA 29/06/2000.

BRASIL. Lei 8.842, de 04 de janeiro de 1994 - Dispõe sobre a política nacional do idoso, cria o Conselho Nacional do Idoso e dá outras providências.

BRASIL. Resolução RDC n. ${ }^{\circ}$ 50, de 21 de fevereiro de 2002. Dispõe sobre o Regulamento Técnico para projetos físicos de estabelecimentos assistenciais de saúde. BRASIL. NBR 9.050/2004. Válida a partir de 30.06.2004. Acessibilidade a edificações, mobiliário, espaços e equipamentos urbanos.

BRASIL. Resolução RDC n. 283, de 26 de setembro de 2005. Art. 1.‥ Diário Oficial da União, Brasília, 2005.

Constituição da República Federativa do Brasil de 1988. Brasília, DF: Senado Federal, 2000. 